\title{
Da Produção como Totalidade
}

Sara Totta ${ }^{1}$

(Centro de Filosofia da Universidade de Lisboa)

A primeira crise mundial da economia capitalista, nomeadamente a crise financeira ocorrida nos anos 50 do século XIX, motivou Karl Marx a organizar sistematicamente as suas pesquisas económicas iniciadas uma década antes, com os conhecidos Manuscritos de Paris. Desse esforço de auto-clarificação surgiu um conjunto de cadernos escritos em jeito de monografia, durante os anos de 1857-58, que serviram de base à primeira publicação económica do filósofo alemão: a Contribuição Para a Crítica da Economia Política, publicada em 1859. Este conjunto de cadernos, postumamente publicados no ano de 1939, ficou conhecido, devido ao seu carácter inacabado, esquemático e fragmentário, pelo título Grundrisse. Se, por um lado, o carácter preparatório destes cadernos não nos apresenta a teoria económica marxiana na sua expressão mais acabada, como encontramos na obra $O$ Capital, os Grundrisse dão-nos pistas sobre o modo como Marx pensou os problemas da economia e quais as principais dificuldades teóricas e metodológicas com que se deparou. Por outro lado, nestes cadernos, encontram-se mais desenvolvidas algumas das teses principais do seu materialismo histórico, algumas já presentes em obras como A Ideologia Alemã, mas acompanhadas agora de um embasamento histórico e económico - e, por conseguinte, apresentando-se de modo mais concreto. De entre estas teses constituintes do novo materialismo de Marx, a reflexão sobre o carácter historicamente determinante e determinado de toda a produção encontra especial desenvolvimento numa pequena introdução que, de tal modo se afigurou ambiciosa e rica nas problemáticas

1 saratotta@gmail.com.

Philosophica, 54, Lisboa, 2019, pp. 45-60. 
que convoca, e para as quais o seu autor não dispunha ainda de uma resposta satisfatória, que acabaria por ser posta de parte e permanecer inacabada. Todavia, o seu valor para os estudiosos de Marx, especialmente no que à dialéctica materialista enquanto método concerne, é inesgotável. Nesta "Introdução" dos Grundrisse, assim como ao longo dos restantes cadernos dedicados ao dinheiro e ao capital, manifesta-se, em acto, a apropriação materialista do método dialéctico de Hegel, ou não fosse este filósofo alemão a terceira fonte mais referida nestes escritos, seguindo-se a Adam Smith e David Ricardo.

No famoso texto introdutório aos Grundrisse, redigido por Marx em 1957, encontramos algumas das mais ricas provas textuais sobre a apropriação marxiana do método dialéctico de Hegel para pensar a lógica interna das relações sociais e económicas do capitalismo. Nomeadamente, destaca-se o questionamento de Marx sobre o método mais adequado para a investigação económica, bem como para a exposição teórica dos seus resultados. Debatendo-se com a dificuldade de eleger um ponto de partida para a teorização económica, o filósofo e revolucionário alemão distingue os dois métodos possíveis para a sua abordagem: a saber, o método analítico, que parte da análise de totalidades, como a população ou o estado, e abstrai relações gerais determinantes, como a divisão do trabalho ou o valor; a via alternativa consiste no procedimento inverso, procedendo-se destas relações mais simples até à reprodução das totalidades onde estas relações operam. Este último constitui o método sintético, que se verifica, nas palavras do próprio autor, como «o único método cientificamente correcto». ${ }^{2}$ Um exemplo da aplicação deste método sintético é A Ciência da Lógica de Hegel, onde o autor parte das determinações mais simples e imediatas, como o ser e o nada, progredindo até categorias ontológicas mais complexas, como a essência e o conceito. Somente através da via sintética se obtém como resultado a reprodução teórica do concreto na totalidade das suas determinações, já que o primeiro método tende a abstrair da particularidade destas determinações, simplificando-as em conceitos gerais. Como Marx observa, as categorias mais simples da economia pressupõem e remetem invariavelmente para outras mais complexas que as determinam e fundamentam. Consideremos o exemplo apresentado pelo autor, nomeadamente, o valor de troca. Este

2 K. Marx, Grundrisse, London: Penguin Books, 1993, p. 101: «As soon as these individual moments had been more or less firmly established and abstracted, there began the economic systems, which ascended from the simple relations, such as labour, division of labour, need, exchange value, to the level of the state, exchange between nations and the world market. The latter is obviously the scientifically correct method.» Doravante esta edição será referida simplesmente como Grundrisse. 
conceito, apesar da sua simplicidade, pressupõe uma população cuja produção se organize segundo relações específicas, assim como uma certa organização política. Por outro lado, apesar de parecer mais adequada a exposição destas categorias segundo a sequência do seu surgimento histórico, esta conexão interna seria, segundo Marx, meramente superficial, pois certas relações de produção determinantes em fases mais avançadas do desenvolvimento económico, como o capital ou o dinheiro, podem coexistir em épocas históricas anteriores, onde não encontram, todavia, as condições para a realização plena das suas determinações, expressando relações secundárias ou subordinadas e de modo algum mediando todos os processos produtivos. A actividade produtiva, considerada abstractamente segundo o conceito geral de trabalho, subsume tanto o trabalho do escravo como o do artesão e do trabalhador assalariado, anulando assim a diferença específica de cada uma daquelas formas de trabalho, na qualidade de fenómenos historicamente determinados. A história das relações de produção e propriedade que antecedem a sociedade capitalista é fundamental para compreender a origem do capital moderno, mas insuficiente para explicar o seu modo de reprodução na moderna sociedade burguesa. Inversamente, para Marx é a compreensão exaustiva das relações de produção capitalista, na medida em que constitui a forma económica mais desenvolvida, que permitirá compreender a especificidade histórica de sociedades menos desenvolvidas.

Na presente comunicação consideraremos a crítica de Marx ao modo abstracto como os principais economistas do seu tempo, nomeadamente Mill, Smith e Ricardo, consideravam a produção. Reconhecendo a produção como o objecto fundamental da ciência económica, os economistas ingleses anteriormente referidos assumiam-na como o único domínio estritamente económico e a sua determinação era o resultado de leis naturais transcendentes de todo o devir histórico. Salientando de igual modo como o método dialéctico, na medida em que se coloca sempre como perspectiva da totalidade, é o único que permite pensar a deveniência e transitoriedade das relações de produção.

\section{A produção em geral}

Observando uma tendência geral dos economistas políticos para introduzirem as suas obras com capítulos dedicados à produção em geral e aos seus pré-requisitos essenciais, a astúcia crítica de Marx leva-o imediatamente a questionar: haverá alguma utilidade em pensar-se numa produção em geral? A produção em geral é, naturalmente, uma abstracção do pensamento. Não existe nenhuma produção geral, nem tão pouco uma 
produção universal. A produção é, sempre, segundo o filósofo, uma produção específica, como a agricultura ou a pesca, ou como totalidade, um conjunto de ramos produtivos, como por exemplo a indústria. Qual o sentido de se pensar de modo abstracto algo que se verifica tão concretamente diverso? A produção, na sua expressão mais universal, é resumida pelo autor do seguinte modo: os indivíduos, em sociedade, apropriam-se das forças e produtos naturais, que transformam segundo as suas necessidades. Marx reconhece que certas categorias e determinações são comuns ao modo de produção de períodos históricos distintos: por exemplo, o trabalho, uma certa divisão do trabalho e os instrumentos de produção disponíveis. Por conseguinte, o autor concede que a abstracção das determinações comuns a todas as formas de produção pode poupar-nos a repetições. O seu conteúdo cognitivo será, porém, bastante limitado, reduzindo-se à enunciação de algumas tautologias. De acordo com a interpretação de Marx, este nível de abstracção serve outros propósitos ideológicos na obra de economistas como John S. Mill. A saber, o de naturalizar categorias, relações e funções económicas exclusivas do modo de produção capitalista: como, por exemplo, quando o economista inglês define o conceito de capital simplesmente como "trabalho objectivado passado" ou "instrumento de produção" e, neste sentido, o afirma como uma condição sine qua non de toda a produção, independentemente da fase de desenvolvimento histórico da sociedade em causa. ${ }^{3}$ Esta consideração unilateral e abstracta do conceito de capital implica, deste modo, que fenómenos e relações económicas tipicamente capitalistas se verifiquem em todas as formas históricas de organização social antecedentes, como observa sarcasticamente Marx:

Por conseguinte, o capital é uma relação geral, eterna, da natureza; isto é, se eu ignorar precisamente aquela qualidade específica que torna o 'instrumento de produção' e 'o trabalho acumulado' em capital. ${ }^{4}$

3 Cf. J. S. Mill, Collected Works, Vol. II, Principles of Political Economy, Indianapolis: Liberty Fund, 2006, p. 55: «It has been seen in the preceding chapters that besides the primary and universal requisites of production, labour and natural agents, there is another requisite without which no productive operations, beyond rude and scanty beginnings of primitive industry, are possible: namely, a stock, previously accumulated, of the products of former labour. This accumulated stock of the produce of labour is termed Capital.»

4 Grundrisse, p. 86. Um exemplo evidente deste emprego anacrónico e a-histórico do conceito de capital é o do militar e economista Coronel Robert Torrens, que na sua obra An Essay on the Production of Wealth, publicada em 1821, identifica o emprego por selvagens de paus e pedras, nas suas caçadas, como a origem do capital. Vide Karl Marx, O Capital, Vol. I, Edições Avante, Lisboa, 1990, p. 213, nota 9. 


\section{Forma silogística da produção}

A produção, a distribuição, a troca e o consumo constituem as categorias fundamentais da teoria económica moderna. Enquanto expressão teórica de processos e relações económicas reais, a ordenação isolada e sequencial, tipicamente verificada nas obras de economia política, torna patente uma compreensão ainda linear e unilateral do circuito de produção de riqueza. Neste circuito de capital produtivo, resumidamente expresso na fórmula produção-mercadoria-dinheiro-mercadoria-produção (P-M-D-M-P), a produção ocupa não apenas o ponto de partida da formação de valor, mas a finalidade última deste processo, a partir do qual se repete novamente este circuito. Esta repetição seria motivada não somente pelo consumo das mercadorias produzidas, mas igualmente pelo facto de algumas das mercadorias consistirem, por seu turno, em novos meios de produção.

Assim, os sujeitos produtores objectivam-se na produção, constituindo os seus produtos uma forma reificada de dispêndio das suas forças físicas e intelectuais. Reconhecendo-se, a partir da teoria de Adam Smith, o trabalho humano acumulado como a substância do valor, o processo de valorização ou produção de valor encerra-se, assim, nas actividades produtivas estritamente compreendidas (agricultura, pesca, indústria, etc.). Por seu turno, a distribuição, entendida estritamente como a alocação proporcional da participação dos indivíduos na riqueza social produzida, é condicionada pela contingência da organização social dos indivíduos segundo classes. Em suma, na distribuição é determinada a porção de riqueza social que cabe a cada indivíduo. A troca é concebida como momento derivado da distribuição, sendo que, pela sua mediação, a troca faz chegar aos indivíduos, segundo o seu arbítrio e necessidades pessoais, os produtos nos quais desejam converter a proporção de riqueza que lhes é distribuída. Finalmente, o consumo, considerado estritamente como consumo individual, constitui um domínio totalmente extra-económico e a sua relevância para o estudo da produção deve-se ao facto de a servir como estímulo para a sua reprodução contínua. Tanto subjectivamente, fornecendo o seu impulso como necessidade, como objectivamente, considerada segundo o seu carácter antitético em relação à produção, como dissolução dos produtos na reprodução física dos consumidores. Ao consumo se reconduziria a finalidade última de toda a produção de riqueza, como podemos ler nos Grundrisse:

[...] ao contrário dos produtos meramente naturais, o produto prova-se enquanto tal, torna-se um produto somente através do consumo. Somente 
através da sua decomposição, o consumo dá ao produto o seu toque final, já que o produto é produção não somente como actividade objectificada, mas antes como objecto para um sujeito activo. ${ }^{5}$

Assim considerado, o circuito linear de geração de riqueza apresenta a coerência meramente sequencial e abstracta dos seus processos, podendo ser reconduzido a uma interpretação silogística onde a produção se afigura como o momento da generalidade, a distribuição e a troca constituem a particularidade, e o consumo a singularidade onde, finalmente, se unificaria a totalidade daqueles momentos. ${ }^{6}$ A dissolução dialéctica da oposição entre produção e consumo constitui o ponto de partida marxiano para a recondução de todas as categorias a momentos da produção e a predominância da determinação desta em relação a todos as outras.

\subsection{Produção e consumo}

Consideremos aquele que é o ponto de partida de Marx para pensar a produção como totalidade: a identidade imediata e mediada da produção e do consumo. Este é provavelmente o momento mais explicitamente hegeliano dos Grundrisse. ${ }^{7}$ Marx coloca-se aqui do lado dos economistas do seu tempo. A crítica que mais frequentemente se dirigia aos economistas políticos era justamente a de cindirem artificialmente a produção em face da distribuição e do consumo, desconsiderando a influência determinante destas duas últimas categorias em relação à primeira. Estas críticas são, da perspectiva marxiana, igualmente infundadas, uma vez que admitem a separação daqueles momentos entre si face ao processo produtivo como um todo.

De acordo com Marx, o conceito económico de consumo produtivo, bem como a teoria da oferta e da procura, demonstram, pelo contrário, quão cientes estavam os economistas políticos das mediações entre a produção e o consumo. Empiricamente, a produção verifica-se, de facto, como uma forma de consumo e, portanto, imediatamente idêntica a este. Como salienta Marx, esta identidade é reconhecida pela teoria económica clássica quando distingue

5 Grundrisse, p. 91.

6 Cf. Ibid., p. 89.

7 A dialéctica entre a produção e o consumo desenvolvida nesta Introdução de 1857, enquanto identidade mediada através da negação de determinações opostas, subsistentes em função da totalidade da sua mútua mediação negativa, encontra um parelelismo evidente com o conceito de Grund, exposto no terceiro capítulo da Doutrina da Essência, na Ciência da Lógica de Hegel. 
adequadamente o consumo produtivo (enquanto consumo de matériasprimas, instrumentos e meios de produção, bem como da força de trabalho) em relação ao consumo individual. É justamente o consumo individual que é colocado pela teoria económica como o inverso da produção, na medida em que o consumo implica a consumição, ou destruição, do objecto produzido. Mas este raciocínio segue-se somente na medida em que os economistas políticos clássicos assumiram apenas a perspectiva do capital, pois deste ponto de vista o consumo individual é improdutivo. Do ponto de vista do indivíduo, o consumo é sempre produtivo - fisiologicamente, por exemplo, quando nos alimentamos, e intelectualmente, quando nos enriquecemos através da educação e da cultura.

A manter-se a oposição que os distingue, a relação entre a produção e o consumo assume ainda um carácter mediado: o consumo sem produtos é impossível, a produção sem consumo é desprovida da sua finalidade. A produção recebe, sob a forma de necessidade subjectiva a suprir, o estímulo para a sua reprodução. Neste sentido, prossegue Marx, o consumo actualiza o produto enquanto produto, que, não sendo consumido, permanece enquanto tal somente como potência. O produto é a objectificação do trabalho - não como fim em si, como actividade objectificada, mas orientado para sujeitos activos. Deste modo, o consumo realiza e dá sentido ao próprio momento produtivo: «Se é evidente que a produção fornece ao consumo o seu objecto exterior, é igualmente claro que o consumo põe idealmente o objecto da produção como imagem interna, como necessidade, impulso e finalidade.. ${ }^{8}$

Inversamente, a produção não se limita a fornecer objectos para consumo, mas produz os próprios consumidores de modo objectivo e subjectivo. Como Marx sublinha, o carácter específico dos produtos implica que sejam igualmente consumidos de um modo determinado. Da mesma forma, a produção cria nos consumidores novas necessidades, que por sua vez adquirem a expressão de impulsos subjectivos para o produto. A produção determina de igual modo a percepção que os consumidores têm dos produtos, cultivando-os, como se verifica no caso da produção artística: «O objecto de arte - como qualquer outro produto - gera um público sensível à arte e capaz de desfrutar da beleza.» ${ }^{9}$

Não obstante a determinação recíproca que se verifica na diversidade de mediações consideradas entre a produção e o consumo, não se conclui de modo algum que estes possam ser identificados. O que se releva, acima de tudo, é que produção e consumo são ambos momentos de um processo, onde

8 Grundrisse, pp. 91-92.

9 Ibid., p. 92. 
a produção é predominante e o verdadeiro ponto de partida.

Contudo, esta reflexão dialéctica, e estritamente formal, sobre os conceitos de produção e consumo adquire uma complexidade maior quando se consideram ambas as esferas no contexto real das relações de produção capitalistas. Uma vez que no modo de produção capitalista desenvolvido se generaliza o trabalho assalariado, a massa de trabalhadores surge aos olhos do capitalista simultaneamente como uma massa de consumidores ${ }^{10}$ e, por conseguinte, de detentores de valor de troca. Assim, salienta Marx, os próprios trabalhadores constituem «[...] outros tantos centros de circulação com os quais a acção de troca se inicia e pelos quais o valor de troca do capital se mantém..${ }^{11}$ Neste caso, seria racional supor que um aumento dos salários dos trabalhadores lhes permitiria uma maior quantidade de valores de troca e, por conseguinte, serviria igualmente o interesse do capitalista. Contudo, é justamente o oposto que se verifica: desde logo, na medida em que nenhum capitalista se relaciona com os seus próprios trabalhadores como consumidores; pelo contrário, o seu interesse reside na redução da sua capacidade de consumo e de compra (isto é, dos seus salários) tanto quanto possível.

Em segundo lugar, Marx recorda a observação de Malthus segundo a qual a possibilidade de realização de lucros com a produção de uma mercadoria pressupõe necessariamente que a procura pela mesma não se esgota na procura dos trabalhadores que a produzem. Por conseguinte, conclui: «a procura dos trabalhadores nunca pode constituir uma procura adequada. $\rangle^{12}$

Por último, a produção de mais-valia encontra-se dependente de um tempo excedente de trabalho não remunerado, isto é, para lá do tempo de trabalho necessário para a produção de uma determinada mercadoria, ${ }^{13}$ o que implica a limitação da capacidade do consumo do trabalhador (o seu salário) ao mínimo necessário para a sua subsistência, ou seja, para a reprodução da sua força de trabalho. Assim, conclui Marx, verifica-se a prevalência das relações de produção (capitalista-trabalhador) sobre as relações de mercado (produtor-consumidor), revelando-se aqui um dos aspectos paradoxais e contraditórios do capital:

10 Excepto os seus próprios trabalhadores, nota Marx.

11 Grundrisse, p. 419.

12 Ibid., p. 420.

13 Que encontraria o seu equivalente quantitativo no salário pago ao trabalhador para apropriação da sua força de trabalho. 
O aumento ilimitado do seu valor - a criação ilimitada de valor - aqui é, portanto, absolutamente idêntica à posição de entraves à esfera da troca, ou seja, à possibilidade da sua realização - a realização do valor gerado no processo produtivo. ${ }^{14}$

Consequentemente, o capital é interpretado por Marx como a unidade desta contradição entre a esfera produtiva e a esfera da sua realização, a saber, a troca. Este carácter contraditório da economia capitalista verificase de igual modo na relação entre produção e consumo, engendrando por seu turno aquela que é considerada pelo filósofo como a contradição fundamental do capitalismo desenvolvido: a sobreprodução. ${ }^{15}$

Passemos agora à consideração das categorias que, tipicamente, os economistas políticos clássicos consideraram como processos exteriores à esfera produtiva.

\subsection{Distribuição, troca e circulação como momentos da produção}

Da perspectiva da economia política clássica, a distribuição define-se, em geral, como a atribuição de uma parcela da riqueza produzida entre os membros de uma sociedade. O modo e a proporção daquela distribuição de riqueza não estaria, segundo o entendimento dos economistas clássicos, dependente de leis estritamente económicas, mas antes do modo como uma sociedade se organiza social e politicamente: nomeadamente, do número de classes sociais que a compõem, da sua forma de governo, do seu código jurídico e tributário, e assim por diante. Esta perspectiva parece correcta, mas, como nota Marx, ela afigura-se limitada, ignorando um aspecto que liga essencialmente a distribuição à produção: a distribuição não destina somente parcelas de da riqueza produzida a classes e consumidores, mas também os meios de produção e a subsunção dos membros de uma sociedade a relações específicas de produção. A tese de John Stuart Mill segundo a qual somente a produção é determinada por leis naturais imutáveis, por

14 Grundrisse, p. 422.

15 «It is enough here to demonstrate that capital contains a particular restriction over production - which contradicts its general tendency to drive beyond every barrier to production - in order to have uncovered the foundation of overproduction, the fundamental contradiction of developed capital [...]», Grundrisse, p. 415. A sobreprodução e a incapacidade de escoamento da produção nos mercados internos, devido aos baixos salários auferidos pelas classes trabalhadoras, foram algumas das principais motivações da primeira grande crise financeira mundial do capitalismo que, como mencionamos no início do presente texto, ocorreu durante a década de 50 do século XIX, precisamente no período de redacção dos Grundrisse. 
oposição ao carácter acidental e convencional dos princípios que regulam a distribuição, é a principal tese visada pela crítica de Marx. Como o filósofo alemão faz notar, não é arbitrário nem meramente convencionado que a distribuição da riqueza na moderna sociedade capitalista sob a forma de renda da terra, salários, juros e lucros, encontre a sua correspondência imediata nos agentes produtivos da terra, trabalho assalariado e capital. A sua correlação é particularmente evidente no caso do capital: este manifesta uma existência fenoménica dúplice, quer como agente de produção quer como fonte de rendimento, pois o juro e o interesse não somente pressupõem o capital como agente produtivo predominante, mas surgem também como modos próprios da sua reprodução. Do mesmo modo, a distribuição de salários a um determinado grupo de indivíduos subentende necessariamente um modo de produção baseado no trabalho assalariado, e, por conseguinte, a existência prévia do capital e da propriedade fundiária como agentes produtivos independentes e contrapostos aos trabalhadores. De acordo com Marx, somente do ponto de vista dos indivíduos singulares que «vêm ao mundo desprovidos de capital e de terra» ${ }^{16}$ é que a distribuição parece determinar previamente o seu destino de assalariados.

A lei que condiciona uma certa estrutura distributiva é, portanto, a mesma que regula o modo de produção que lhe serve de fundamento material. Além disso, na medida em que inclui a distribuição dos próprios instrumentos e agentes de produção, constitui-se simultaneamente como um momento da totalidade da produção, não devendo de modo algum ser pensada separadamente do seu conjunto de relações. No final do sétimo caderno dos Grundrisse, Marx vai mesmo mais longe, afirmando a identidade dos dois tipos de relação, sub specie distributionis. Numa clara alusão ao termo espinozano sub specie aeternitatis, conclui que a sua aparente distinção é apenas uma questão de perspectiva:

As 'leis e condições' da produção de riqueza e as leis da 'distribuição de riqueza' são as mesmas leis segundo formas diferentes, ambas são mutáveis e sofrem o mesmo processo histórico; constituem enquanto tal apenas momentos de um processo histórico. ${ }^{17}$

No que diz respeito à troca e à circulação, esta última a expressão da totalidade das trocas numa sociedade, apesar de desempenharem evidentemente uma função mediadora entre a produção e o consumo, Marx subsume-as

16 Cf. Grundrisse, p. 96.

17 Grundrisse, p. 832. 
igualmente como momentos da produção. Desde logo, qualquer actividade produtiva particular implica a troca entre fornecedores de matérias-primas e instrumentos de produção, como por exemplo no caso da maquinaria empregue na indústria e na agricultura. No que diz respeito ao modo de produção capitalista, a própria força de trabalho é vendida como mercadoria ao capitalista em troca de um salário. Deste modo, aquela força torna-se capital e somente enquanto tal é considerada produtiva, como sublinha Marx no terceiro caderno sobre o capital:

Esta transformação é posta somente no interior do próprio processo de produção. Assim, a questão sobre a produtividade ou falta de produtividade do capital é absurda. O trabalho é que é somente produtivo se for absorvido pelo capital, onde o capital forma a base da produção e onde, consequentemente, o capitalista controla a produção. ${ }^{18}$

No que concerne à troca e circulação, o desenvolvimento do sistema de trocas também se encontra dependente da organização das relações de produção. Concretamente, depende da divisão do trabalho e da existência de uma produção de carácter privado. A intensidade, a extensão e a forma como o sistema de trocas se configura estão igualmente condicionadas pelo desenvolvimento da estrutura produtiva. Nas sociedades capitalistas modernas, ser-nos-ia difícil conceber a existência do moderno mercado mundial, por exemplo, sem que antes se tivessem desenvolvido as forças produtivas da indústria e a sua apropriação de actividades produtivas historicamente precedentes, como a agricultura. No modo de produção capitalista, a circulação de mercadorias constitui o momento-chave da realização da mais-valia e, por conseguinte, da reprodução do capital ou da sua depreciação, devendo por isso ser igualmente considerada como um momento do processo produtivo. A lógica que Marx estabelece entre a produção e a circulação como unidade específica do capital é desenvolvida no quinto caderno dos Grundrisse: «A circulação do capital realiza o valor, enquanto o trabalho vivo cria o valor.» ${ }^{19}$ Porém, como já observámos anteriormente no contexto da produção e do consumo, esta relação entre produção e circulação encerra igualmente as suas contradições internas.

A circulação assoma, no modo de produção capitalista, num momento essencialmente produtivo, na medida em que é na circulação de capitais e mercadorias que se realiza efectivamente a mais-valia. Nesta forma

18 Ibid., p. 308.

19 Ibid., p. 543. 
económica de organização social, a circulação de mercadorias não desempenha apenas a função mediadora entre produtores e consumidores, constituindo-se antes como o momento de realização do fim último de toda a produção. Todavia, esta determinação formal da categoria da circulação, no sistema de produção capitalista, é ignorada na teoria económica clássica, que tende a considerar a circulação somente como totalidade de trocas directas entre mercadorias e, por conseguinte, como uma extensão maior de trocas entre valores equivalentes. Se a circulação é compreendida como realização do circuito Mercadoria-Dinheiro-Mercadoria (M-D-M), é impossível que seja retirado um valor maior do que aquele que é lançado no mercado. Neste circuito, os extremos, a saber, duas mercadorias diversas, colocam-se numa mera relação de equivalência de valor (trabalho social objectivado), mediada por uma quantia de dinheiro, funcionado aqui como simples equivalente e meio de troca. Por outro lado, no circuito M-D-M, o seu término e finalidade é o consumo de uma mercadoria de que haja necessidade, mas que não se produza imediatamente através do trabalho. Por exemplo, um padeiro vende o seu pão, isto é, troca-o por dinheiro que posteriormente troca de novo por outras mercadorias para o seu consumo. O circuito de mercadorias na economia capitalista constitui precisamente o oposto deste movimento: representando-se pela fórmula D-M-D, cuja finalidade última não consiste no consumo, mas no aumento do valor de troca que é colocado inicialmente no mercado:

A este incremento ou excesso sobre o valor originário chamo eu maisvalia (surplus value). O valor originariamente adiantado não apenas se mantém, portanto, na circulação, mas nela altera a sua magnitude de valor, acrescenta uma mais-valia ou valoriza-se. E este movimento transforma-o em capital. ${ }^{20}$

No caso do circuito D-M-D, ao contrário do que se observa no circuito M-D-M, onde no final a mercadoria se retira do circuito para o consumo individual, a sua repetição é ilimitada e nunca abandona este circuito, já que a quantia de dinheiro inicialmente utilizada para a compra de $\mathrm{M}$ retorna ao mercado para reiniciar o processo reprodutivo. Simplificando, este circuito tem a forma D-D', onde a mercadoria é assumida estritamente como simples portadora de valor de troca - ou, para utilizar a terminologia marxiana, como forma fenoménica particular do valor.

20 K. Marx, O Capital, Vol. I, Lisboa: Edições Avante, 1990, p. 176. Doravante referirnos-emos a esta edição simplesmente como $O$ Capital, Vol. I. 
Assim, o que no primeiro circuito (M-D-M) se afigura como uma determinação qualitativa da mercadoria, o valor, como substância comum que permite a equivalência entre dois valores de uso concretamente diversos, surge agora no circuito capitalista (D-M-D) como o próprio sujeito deste processo de valorização: ${ }^{21}$

De facto, porém, o valor torna-se aqui o sujeito de um processo em que ele, com a constante troca das formas de dinheiro e mercadoria, modifica a sua própria magnitude - enquanto mais-valia afasta-se de si mesmo como valor originário, valoriza-se a si mesmo. [...] $\mathrm{O}$ valor torna-se, pois, valor em processo, dinheiro em processo e, enquanto isso, capital. ${ }^{22}$

\section{Conclusão}

A necessidade de compreender a produção não apenas como o conjunto de actividades produtivas materiais, mas como uma totalidade processual que inclua e articule todos os processos económicos (nomeadamente a distribuição, a circulação e o consumo) verifica-se, assim, como uma exigência metodológica imposta pela própria natureza do modo de produção capitalista. Este modo de produção não se caracteriza somente pela produção de mercadorias e serviços de acordo com as necessidades impostas pelo consumo. Pelo contrário, o que caracteriza essencialmente o modo de produção capitalista - e que, segundo Marx, o distingue de todos os modos de produção anteriores - é a produção de mais-valia, independentemente das necessidades de consumo efectivamente reais. Como vimos anteriormente, a crítica ao modo abstracto como a produção capitalista é concebida estende-se igualmente ao conceito de circulação de mercadorias que, tanto Adam Smith como Mill, consideravam ainda como uma extensão meramente quantitativa da troca simples de mercadorias: isto é, uma relação de troca entre valores equivalentes. Partindo de um conceito de circulação, as principais teorias da economia política clássica excluíram, por conseguinte, o papel central de valorização (ou realização de valor) que se opera no interior da circulação de mercadorias. Esta é, na perspectiva marxiana, a determinação formal que distingue essencialmente a produção capitalista das formas produtivas anteriores: o trabalho, que anteriormente satisfazia directamente a maioria das necessidades imediatas

21 A aplicação concreta e material do conceito hegeliano de substância que se torna sujeito no seu auto-desenvolvimento. Vide Hegel, Phenomenology of Spirit, 1977, Oxford: Oxford University Press, pp. 37-38.

22 O Capital, Vol. I, p. 180. 
dos indivíduos, adquire uma determinação formal distinta como trabalho social, e só mediatamente (através da sua troca por um salário) é capaz de suprir as mesmas necessidades. O trabalho surge, então, como uma mercadoria que deve necessariamente ser trocada para se tornar produtiva:

O que caracteriza, portanto, a época capitalista é que a força de trabalho assume para o próprio operário a forma de uma mercadoria a ele pertencente e o seu trabalho a forma de trabalho assalariado. Por outro lado, generaliza-se apenas a partir deste momento a forma-mercadoria dos produtos do trabalho. ${ }^{23}$

Assim, para uma compreensão adequada das categorias e relações económicas que, como indicámos inicialmente, se constatam empiricamente em períodos históricos e modos de produção diversos, é necessário não apenas o estudo dos seus dados empíricos, mas acima de tudo a identificação das funções determinadas que operam nas relações produtivas em cada um dos sistemas de produção. A consideração meramente empírica e abstracta das categorias consideradas não apenas anula a sua determinação histórica, como também o carácter contraditório da sua determinação recíproca enquanto totalidade do processo produtivo baseado no capital. A insuficiência do método empirista na sistematização teórica do modo de produção capitalista verifica-se, mesmo que inconscientemente, como uma interpretação ideológica e apologética por parte da economia política clássica.

Partindo de um ponto de vista histórico e dialéctico, Marx não compreende as categorias económicas como a expressão de relações de produção acidentais ou meramente convencionais, mas como resultado necessário do predomínio de um determinado modo de produção. As contradições identificadas no sistema de produção capitalista devem, de acordo com Marx, encontrar a sua fundamentação no próprio funcionamento essencial do sistema, e não em factores extra-económicos, de carácter psicológico ou antropológico. ${ }^{24} \mathrm{Na}$ perspectiva do autor d'O Capital, tão pouco a economia se ocuparia de fenómenos dotados de uma essência imutável, que permanecesse idêntica a si mesma, independentemente das suas relações num corpo social produtivo. O carácter anacrónico das teorias sobre a produção de Mill e Adam Smith, não descurando os seus

23 O Capital, Vol. I, p. 197, nota 41.

24 Nas teorias da economia política clássica encontramos frequentemente factores extraeconómicos, muitas vezes morais, psicológicos e antropológicos, como elementos determinantes: por exemplo, imperfeições morais da "natureza humana" como a cupidez, a avareza ou o egoísmo. 
tons ideológicos, é fortemente condicionado pela sua ontologia materialista não dialéctica, estritamente empirista. Um dos inestimáveis contributos dos escritos económicos de Karl Marx, como verificamos nos Grundrisse e n'O Capital, consiste na sua interpretação materialista e dialéctica da articulação entre essência e fenómeno. Considerados como totalidades concretas e históricas, os fenómenos não se esgotam nas suas propriedades sensíveis, nem tão pouco na sua aparência imediata. As determinações e propriedades dos fenómenos são condicionados pelas relações funcionais que estabelecem em sistemas. Esta dialecticidade interna na determinação de realidades concretas é particularmente exemplificada pelo fenómeno do capital e do dinheiro, acerca dos quais comenta Marx, no quinto caderno do capítulo dedicado ao capital:

O dinheiro permanece sempre a mesma forma no mesmo substrato; e pode por isso ser concebido mais facilmente como uma simples coisa. Mas uma e a mesma mercadoria, dinheiro, etc., pode representar capital ou renda, etc. Assim, é claro até para os economistas que o dinheiro não é algo tangível; mas essa uma e mesma coisa pode ser subsumida por vezes sob a designação de capital, outras vezes sob outra designação contraditória, e ser e não ser capital respectivamente. É evidente que é uma relação e só pode ser uma relação de produção. ${ }^{25}$

As relações de produção, na qual os indivíduos se subsumem independentemente da sua consciência e arbítrio, são directamente condicionadas pelo grau de desenvolvimento de forças produtivas materiais. A pressuposição de diferentes graus de desenvolvimento das forças implica logicamente que estas não sejam desprovidas de deveniência histórica, e que as condições que determinam esta deveniência possam não verificar-se em todos os estágios de desenvolvimento social humano. Este é o princípio fundamental do materialismo histórico de Marx. O que procurámos explicitar na presente comunicação é que o carácter dialéctico que esta nova ontologia materialista pressupõe não se prende somente com uma opção metodológica quanto à apreensão teórica e explicativa do objecto de estudo marxiano, a saber, a moderna sociedade burguesa, mas é exigida pela própria historicidade imanente aos modos de produção. Pensar historicamente a produção social humana implica que as suas formas fenoménicas não possam esgotar em si a sua fundamentação essencial, exigindo-se para a sua inteligibilidade plena a sua integração no todo processual.

25 Grundrisse, p. 514. 


\title{
Referências Bibliográficas
}

Hegel, Georg Wilhelm Friedrich (2010), The Science of Logic. Trad. George di Giovanni. Cambridge: Cambridge University Press.

Hegel, Georg Wilhelm Friedrich (1977), Phenomenology of Spirit. Trad. Arnold Vincent Miller. Oxford: Oxford University Press.

Marx, Karl (1970), Grundrisse. Trad. Martin Nicolaus. London: Penguin Books. Marx, Karl (1990), O Capital. Trad. José Barata-Moura et al. Lisboa: Edições Avante.

Mill, John Stuart (2006), Collected Works, Vol. II. Indianapolis: Liberty Fund.

\section{RESUMO}

Pretendemos analisar a abordagem materialista da categoria de totalidade desenvolvida por Marx, nomeadamente a sua aplicação teórica na interpretação dialéctica do conceito de produção no sistema económico capitalista.

Palavras-chave: Totalidade - Produção - Materialismo Dialéctico - Grundrisse

\begin{abstract}
We intend to analyse the materialistic approach to the category of totality developed by Marx, namely in its theoretical application to the dialectical interpretation of the concept of production in the capitalist economic system.
\end{abstract}

Keywords: Totality - Production - Dialectical Materialism - Grundrisse 